\title{
A Strategic Management Framework for the Commercialization of Multi-Technology Renewable Energy Systems: The Case of Concentrating Solar Power in South Africa
}

\author{
Gregory S Prentice \\ Department of Industrial Engineering, \\ Stellenbosch University \\ Stellenbosch, South Africa \\ gskprentice@gmail.com
}

\author{
Imke $\mathrm{H}$ de Kock \\ Department of Industrial Engineering \\ Stellenbosch University \\ Stellenbosch, South Africa \\ imkedk@sun.ac.za
}

\author{
Alan C Brent \\ Department of Industrial Engineering, and \\ the Centre for Renewable and Sustainable \\ Energy Studies \\ Stellenbosch University \\ Stellenbosch, South Africa; \\ Sustainable Energy Systems, Engineering and \\ Computer Science, Victoria University of \\ Wellington, New Zealand \\ acb@sun.ac.za
}

\begin{abstract}
Globally, the importance of sustainable development is recognized due to a number of interconnected social, environmental, and economic challenges. One of the key tenets of sustainable development is the introduction of clean energy, and specifically renewable energy technologies (RETs). The acceleration of the adoption of RETs, however, requires an increase in the rate of commercialization of such technologies; classified as multi-technology renewable energy systems (MTRESs) due to the hierarchical nature of such systems, with differing commercialization-based needs. A strategic management framework was designed as a tool to support the development of strategies for increasing the commercialization rate of MTRESs, and applied to the case of concentrating solar power (CSP) in South Africa. The framework serves as a proof-of-concept, given the current industry constraints, due to political uncertainties in the energy sector of the country, and the theoretical validation process followed. While commercialization prospects for CSP technologies in South Africa could be improved through positioning the country within the global production network of CSP technologies, it is difficult to commercialize a technology for a foreign market. In addition, the paper encourages dialogue on how different stakeholders may be mobilized in the interests of a given technology, while continuing a recent trend in literature, which seeks to move the conversation from energy analysis to practical measures, aimed at hastening efforts towards a sustainable energy transition.
\end{abstract}

Keywords- Commercialisation, Strategy Management, Technology Management, Sustainable Development

\section{INTRODUCTION}

Recent evidence has made it clear that a transition to a more sustainable energy sector containing a greater share of renewable energy technologies (RETs) is taking place [1]. However, the global energy supply is still dominated by fossilfuel technologies [2]. In fact, the actual percentage contribution of RETs to the global energy supply has changed little over the past four decades (see Fig. 1), with the primary shift being that

of oil to coal, nuclear, and natural gas. The renewable energy (RE) industry (hydro, biofuels and waste, and others), on the other hand, has grown by only $1.3 \%$. This lack of substantial change can be understood further with reference to Fig. 2, comparing the levels of growth in the global energy supply of different energy technologies over the same time period.

1973
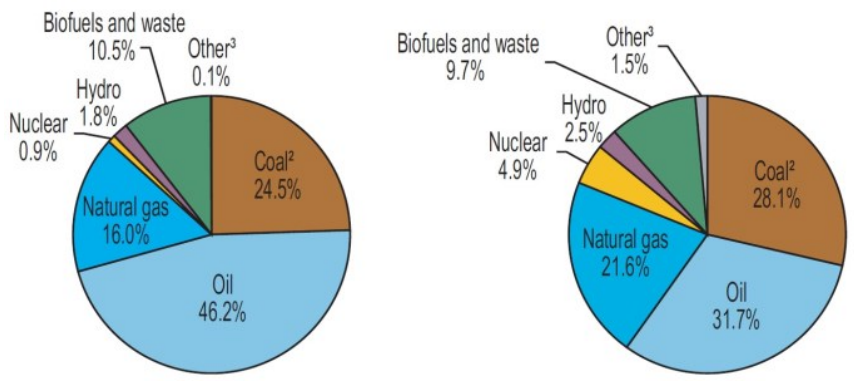

Fig. 1: Composition of the global energy supply - 1973 vs 2015 [2]

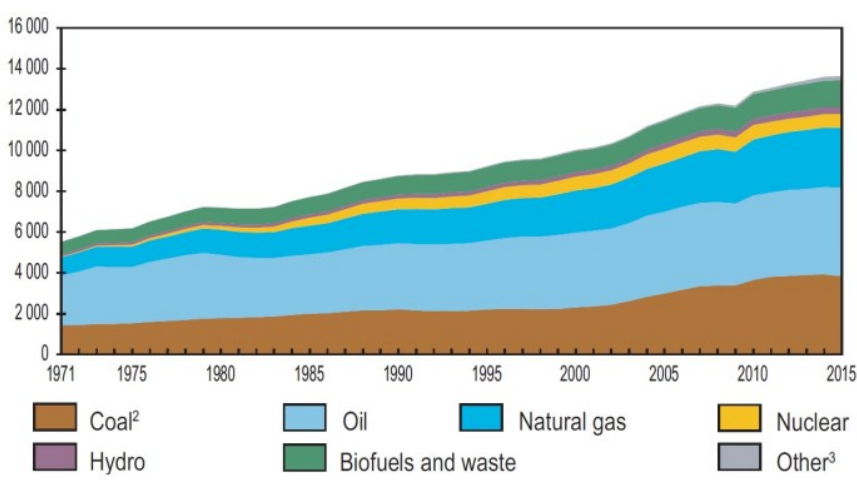

Fig. 2: Growth in the global energy supply $1971-2015$ by fuel (million tonnes oil equivalent) [2] 
The lack of significant change in the energy sector so far is perhaps to be expected, given that despite efforts to "speed up the development, diffusion and implementation of RETs, experience in different countries show that this is a very slow and tedious process" [3]. Indeed, if one considers past transitions, which had taken place within the global energy sector, it is often a decades-long process owing to the complexities of the technological system in place, which comprises multiple integrated technologies, infrastructure, and institutions [4].

Yet, there is cause for optimism. Kern \& Rogge [5] highlight how the transition to a sustainable energy supply may differ from previous large-scale energy transitions in a number of ways. Past energy transitions have often not been managed purposefully, in contrast to the modern era where there is widespread engagement between many stakeholders actively pursuing such a transition. Furthermore, there is international consensus for a more sustainable energy supply, demonstrating that the necessary political will exists. Lastly, the use of global innovation dynamics can also be harnessed to increase the rate at which the sustainable energy transition is able to take place.

While acknowledging that there are practical limits concerning (the speed of) such transitions [4], in order to realize the target of a sustainable energy supply as soon as possible, there is a need to increase the rate at which RETs are adopted into the global energy mix. Yet this is no simple task, given that "despite many efforts of governments, multilateral institutions, NGOs, and even a number of companies and investors, there has been no sustained takeoff" [6]. The task is complicated further in the face of the numerous (systematic) barriers currently limiting the development and diffusion of RETs up the s-curve (see Fig. 3) [3].

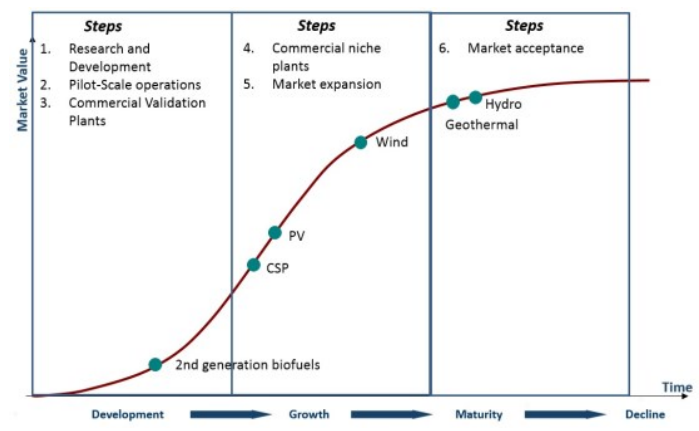

Fig. 3. Global technology life cycle position of RETs [7]

In order to increase the rate at which RETs are adopted into the global energy mix, there is a need to increase the rate of commercialization of such technologies. By increasing the rate of commercialization, namely the speed at which RETs are able to reach the market, it is likely that the time taken for RETs to reach maturity will be reduced, with the net result that they are more likely to present a feasible option regarding the choice of which energy technology to use, sooner. Once RETs are able to compete on a level basis with other energy technologies, it is likely that the environmental benefits they offer will cement their status as a preferred energy technology, enabling greater progress to be made towards a global sustainable energy transition, and thus contributing towards sustainable development.

\section{A. Multi-technology renewable energy systems}

It is important to recognize that of the numerous technologies that comprise RE systems, many may already be considered commercialized, such as pumps, turbines, and compressors [8]. To address this case, the term multi-technology renewable energy system (MTRES) is introduced. 'Multi-technology' acknowledges the hierarchical nature of such systems, and the differences in the state of commercial maturity, while 'renewable energy system' is used as an umbrella term to describe the integrated collective of technologies used to harness power from RE sources. Thus, while the term MTRES is essentially conceptual in nature, it holds value in drawing attention to the need to distinguish commercialization efforts between those technologies which are already commercialized, and those technologies that lie in a pre-commercialized state.

One of the prominent challenges encountered with $\mathrm{RE}$ is the variable nature of supply [9]. This has led to a strong focus on the use of energy storage technologies (ESTs), which are able to store energy and thus extend the hours of energy generation [10]. A popular EST is that of thermal energy storage (TES), which stores energy in the form of heat [9]. One MTRES that is particularly suitable for integration with TES technology is concentrating solar power (CSP) [9]. CSP technologies present a viable means of storing and providing energy when needed, overcoming one of the chief barriers to the widespread use of MTRESs [11]. Furthermore, CSP technologies have the potential for system hybridization, as well as being a scalable technology [11]. Lastly, given CSP's relative immaturity compared to other energy technologies (see Fig. 3), it presents an interesting case study for exploring how the rate of commercialization of MTRESs may be increased.

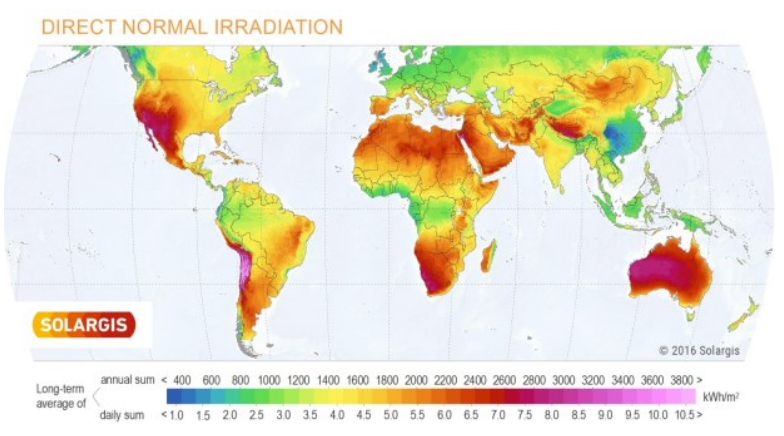

Fig. 4. Global DNI solar map [12]

Fig. 4 presents a direct normal irradiation (DNI) map of the world's solar irradiation resources. As shown, Southern Africa has some of the best solar resources, together with Australia, and the western coasts of North and South America. However, despite the abundance in solar resources, the CSP industry in 
South Africa, the regional powerhouse of Southern Africa, remains largely underdeveloped [11]. Hence, this paper focuses on the case of CSP technologies in South Africa.

Before proceeding, it is necessary to define the scope of this paper. This is important given that CSP technologies represent an entire class of solar energy generation technologies, with different variations in design type and types of energy production (electricity and thermal energy), while also allowing for the inclusion of TES technologies. Considering that new technologies and design variations are being explored with respect to CSP technologies, the decision was made to take a macro-level view of the technology class, and examine efforts that could be implemented to the benefit of all associated technologies. Fig. 5 illustrates the scope, with the vertical axis containing the entire class of CSP technologies, while the horizontal axis comprises the commercialization process (see section 2). Finally, the focus on South Africa is represented by the dotted square encompassing the entire figure.

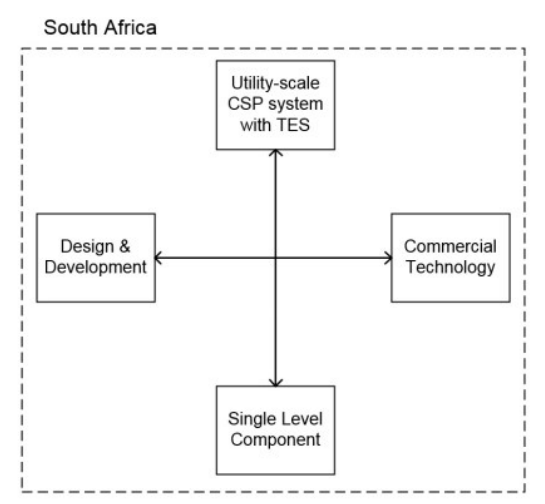

Fig. 5. Research study scope

\section{TECHNOLOGY COMMERCIALISATION}

The field of technology commercialization is one that is receiving greater attention, from firms eager to preserve and improve their source(s) of competitive advantage amidst an increasingly competitive business environment [13], as well as in the policy domain and social science fields given the close interaction of technologies with consumer habits and lifestyles, business models, and socio-political structures [14]. However, it remains a complex subject, possessing different meanings and connotations to different individuals [15].

Scott [16] defines technology commercialization as the "process of introducing a new product or system into the market using new or improved techniques or tools", "moving a technology from laboratory to market acceptance and use, taking it to the mainstream economic activity" [6]. Through commercialization, a technology is able to compete with other established technologies, satisfying expectations relating to its performance and reliability, while being available at a cost the consumer is willing to pay [6].

There is some debate over the set of activities that comprise the commercialization process. Aslani [17] describes the process as beginning with an initial idea, before undergoing a process of technological improvement until a final product or service is developed. Balachandra et al. [6], on the other hand, define only the later stages of the innovation chain as forming the commercialization process (see Fig. 6). A third classification of the process is presented by Lund [18], detailing different activities required during pre- and post-market breakthrough. For the purposes of this study, the process is defined as beginning with the design and development stage, and reaching completion once a final product or service has been delivered to the market.

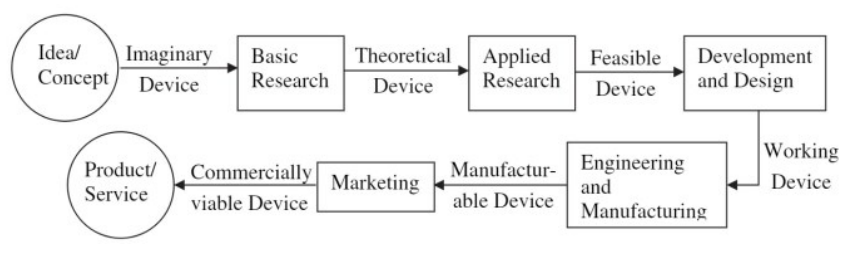

Fig. 6. Innovation chain

\section{A. Commercialization of energy technologies}

The commercialization of energy technologies differs significantly from that of standard technologies, in part due to the politicized nature of energy sectors worldwide [19]. In the past, the commercialization process had been driven predominantly by government-related efforts [6], determining which energy technologies to utilize, while maintaining significant control over the entire process. This has begun to change with the liberalization of energy markets, although the sector remains tightly regulated [20]. However, the wisdom of relying solely on government action to commercialize MTRESs is questionable, given the apparent inability, or unwillingness, to pursue the large-scale commercialization of MTRESs, with many yet to reach a fully commercial state [6]. As such, it may be that other elements should also play a role in the process, and which need to be considered.

\section{THE USE OF CSP IN SOUTH AFRICA}

\section{A. Overview of CSP technologies}

There are presently four different types of CSP technology: parabolic trough, parabolic dish, Linear Fresnel collector (LFC), and central receiver (see Fig. 7) [9]. It is still uncertain which one may emerge as the dominant design, both globally and in South Africa [21]. For the foreseeable future, the parabolic trough collector (PTC) is seen as the most likely contender, while the solar tower central receiver (CR) type has the potential to produce a significant amount of electricity at low cost [11]. On the other hand, LFC technology is favored over PTC for smaller, lower temperature uses, such as industrial process heat and small-scale power [11]. 


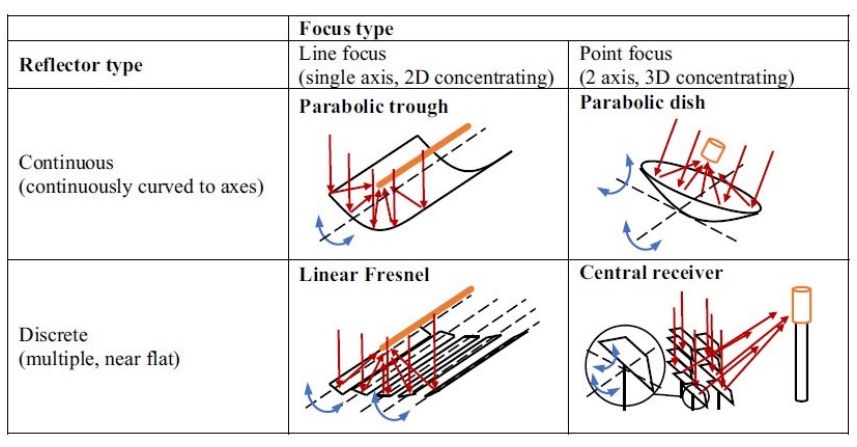

Fig. 7. CSP technology overview [9]

\section{B. The CSP industry in South Africa}

The CSP industry in South Africa is currently in an early stage of development, with only a small number of CSP projects having been commissioned under the country's Renewable Energy Independent Power Producer Procurement Programme, or REI4P [9], as summarized in Table I. There are many barriers limiting the rollout of CSP technologies, of which cost is often highlighted as being the greatest [11], together with limited knowledge of the technology [22]. Furthermore, the fact that South Africa currently possesses the necessary resources, skills, and infrastructure to aid the construction of such plants, and advance the CSP industry [23], points to a lack of willpower to utilize these assets to achieve progress in the learning process of CSP technologies.

TABLE I. CSP PROJECTS UNDER THE REI4P [24]

\begin{tabular}{|l|c|c|c|}
\hline \multicolumn{1}{|c|}{ Project } & Capacity & Bid Round & Status \\
\hline Kaxu & $100 \mathrm{MW}$ & 1 (single tariff) & Operation \\
\hline Khi & $50 \mathrm{MW}$ & 1 (single tariff) & Construction \\
\hline Bokport & $50 \mathrm{MW}$ & 2 (single tariff) & Construction \\
\hline Xina & $100 \mathrm{MW}$ & 3 (time-of-day tariff) & Construction \\
\hline Llanga & $100 \mathrm{MW}$ & 3 (time-of-day tariff) & Construction \\
\hline Redstone & $100 \mathrm{MW}$ & 3.5 (time-of-day tariff) & Development \\
\hline Kathu & $100 \mathrm{MW}$ & 3.5 (TOD tariff) & Development \\
\hline
\end{tabular}

It is also worth comparing the cost of CSP technologies to other energy technologies in South Africa. Given that the only CSP technologies in the country currently exist on a utility scale, the cost comparison is made on a similar scale. Fig. 8 compares the reduction in average tariffs under the REI4P for solar PV, CSP and wind technologies, while Fig. 9 compares the lifetime cost per energy unit of various energy technologies, based on new build capacity values. While it interesting to examine how CSP compares to other energy technologies on a cost basis, one must be careful when making any decisions based on the data, taking into account additional factors such as the capacity factor of the different technologies, value proposition, and energy demand patterns.

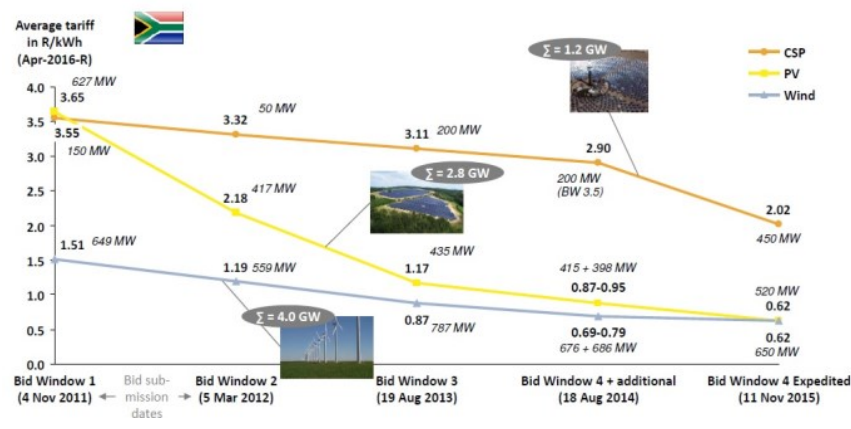

Fig. 8. Solar and wind cost reduction trends under the REI4P [25]

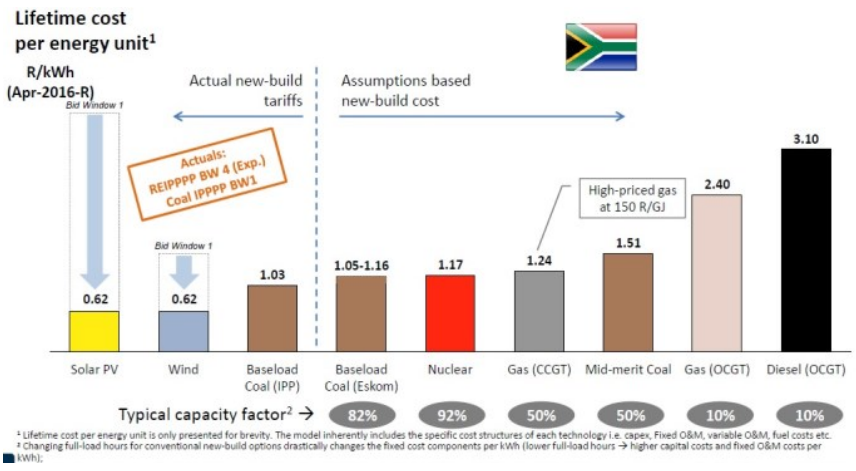

Fig. 9. Lifetime cost comparison of energy technologies [25]

\section{StRATEGiC MANAGEMENT FRAMEWORK}

Following an evaluation of various strategies, approaches, and techniques used for the commercialization of MTRESs [26], a strategic management framework was designed as a tool to support the development of strategies to increase the rate of commercialization CSP technologies in South Africa. The methodology that was employed is outlined in Fig. 10.

A grounded theory approach was used to validate the framework, together with a hybrid-Delphi technique. Relevant experts from academia, government institutions, and industry were engaged within groups of three, and their inputs were incorporated towards improving the framework. The groups were engaged in sequence, thus forming a process of iterative refinement with respect to the framework. Following five rounds of iteration, the final framework developed is presented in Fig. 11. Although the framework was applied to a specific case, the effort was made during the design process to keep the framework as generic as possible, in order to facilitate its possible use with other MTRESs. 


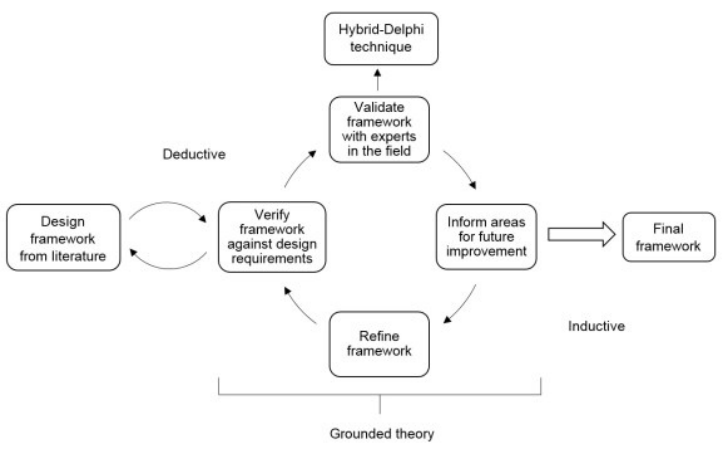

Fig. 10: Framework design methodology [26]

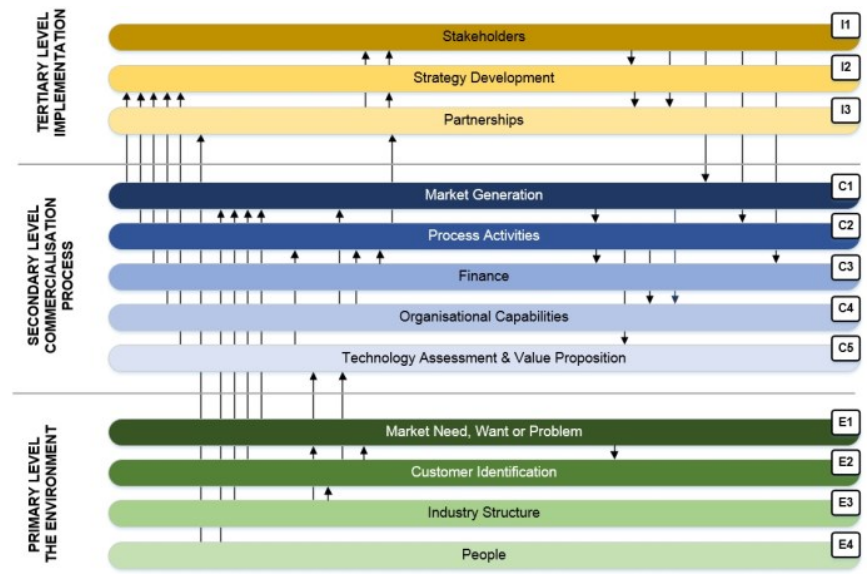

Fig. 11. Strategic management framework [26]

The framework comprises three levels. The primary level is the environment in which the commercialization process takes place. This is guided by the need to ensure that the identified market need, want, or problem continues to exist throughout the commercialization process, and that the relevant customer still holds an interest in the given technology once it reaches the market. The environment is also influenced by the relevant industry structure, comprising factors such as policy and legislation, social and cultural factors, as well as the existing commercialization mechanism, which in South Africa is integrated resource planning through tender bid programmes such as the REI4P [24], although certain government projects are still in development, such as the Medupi and Kusile coal power stations [27]. Lastly, the people component highlights the impact that the behavioral traits and decision-making processes of key influential stakeholders may have on the commercialization environment.

The secondary level relates to the commercialization process itself. This level contains several different components, which are aimed at addressing the different elements of the commercialization process, from recognition of the activities themselves, to measures and tools aimed at market generation, securing new forms of finance, and analyzing different facets of the technology, as well as which organizational capabilities are required. These components present different tools and mechanisms to be used by commercialization practitioners for these respective purposes.

The tertiary level focuses on the implementation of the framework, namely: the development of strategies to increase the rate of commercialization. This includes the identification of the relevant individuals most likely to make use of the framework, and which stakeholders need to be engaged with to increase the rate of commercialization achieved. Furthermore, the framework provides guidance on how strategies may be developed, emphasizing the importance of partnerships in order to address the many tools and activities listed in the secondary level. Lastly, the interfaces and relationships which exist between the different components of each level are illustrated by the black arrows.

\section{RESULTS AND CONCLUSIONS}

Following completion of the validation process, it became apparent that the framework would not be able to achieve the stated objectives, given the present structure of South Africa's energy sector, and the stance taken by the national government regarding the future inclusion of CSP technologies into South Africa's energy mix on a large scale. Despite many participants of the validation process complementing the comprehensive nature of the framework, the weak market prospects, and possible loss of technology champions likely to make use of such a tool, bring into question the potential effectiveness of any strategy developed through use of the framework. These constraints, coupled with the theoretical validation process followed, which cannot be said to be a definitive substitute for any lessons learnt through practical implementation, position the framework as a proof-of-concept approach of how the rate of commercialization may (theoretically) be increased, should industry conditions permit.

Returning to the identified research problem, to increase the rate of commercialization of CSP technologies, to achieve such a goal there is a need to leverage South Africa's position in the global production network (GPN) of CSP technologies. Alternative commercialization prospects should be explored internationally, where joint commercialization or technology transfer strategies could be used for the commercialization of knowledge, skills, or small-scale CSP technologies, such as the Helio100 project [23]. However, it is important to recognize the difficulties involved in commercializing a technology for a foreign market.

Finally, the study also contributes towards a recent trend in literature, which aims to move the debate from the analysis of energy transitions towards practical measures aimed at increasing the speed at which such transitions occur, thus accelerating progress towards a sustainable future.

\section{RECOMMENDATIONS}

One of the challenges highlighted during the formation of partnerships was how to achieve buy-in from a wide range of stakeholders. In this regard, it is important to consider the role 
played by innovation networks, and how they can be utilized for such a purpose. While the framework did attempt to address this issue through the identification of people, the factors behind their behavior, interests, and decision-making, and the focus on relevant stakeholders and means of strategy development, there is scope for the development of a framework that examines in detail how one may secure buy-in from multiple stakeholders (in the South African context). In addition, it may be worthwhile investigating the processes that lead to such support in the way of decision-making and behavioral traits, with a strong focus on those members of government with significant influence over the state of the existing energy sector. Although other research opportunities also exist, such as the practical implementation of the framework, the use of the framework with other MTRESs, such as solar PV or second-generation biofuels, and how a greater rate of commercialization may contribute to sustainable energy and development efforts, investigating means of mobilizing different stakeholders towards a common goal (increasing the rate of technology commercialization) is currently viewed as having the highest priority.

\section{REFERENCES}

[1] J. Meadowcroft, "What about the politics? Sustainable development, transition management, and long term energy transitions," Policy Sci., vol. 42, no. 4, pp. 323-340, 2009.

[2] International Energy Agency, "Key World Energy Statistics 2017," $2017 . \quad$ [Online]. Available: http://www.iea.org/publications/freepublications/publication/KeyW orld2017.pdf. [Accessed: 02-Feb-2018].

[3] S. O. Negro, F. Alkemade, and M. P. Hekkert, "Why does renewable energy diffuse so slowly? A review of innovation system problems," Renew. Sustain. Energy Rev., vol. 16, no. 6, pp. 3836-3846, 2012.

[4] A. Grubler, C. Wilson, and G. Nemet, "Apples, oranges, and consistent comparisons of the temporal dynamics of energy transitions," Energy Res. Soc. Sci., vol. 22, no. 2016, pp. 18-25, 2016.

[5] F. Kern and K. S. Rogge, "The pace of governed energy transitions: Agency, international dynamics and the global Paris agreement accelerating decarbonisation processes?," Energy Res. Soc. Sci., vol. 22, no. 2016, pp. 13-17, 2016.

[6] P. Balachandra, H. S. Kristle Nathan, and B. S. Reddy, "Commercialization of sustainable energy technologies," Renew. Energy, vol. 35, no. 8, pp. 1842-1851, 2010.

[7] S. Grobbelaar, Technology Management 873 Class Notes: STI Policy and supporting policy-making. Stellenbosch: Department of Industrial Engineering, Stellenbosch University, 2016.

[8] B. Conrad, "Turbomachinery \& International Pump Users Symposia sees another record-breaking year," Texas A\&M Engineering Experiment Station, 2016. [Online]. Available: http:/tees.tamu.edu/news/2016/09/26/turbomachinery-internationalpump-users-symposia-sees-another-record-breaking-year/.

[Accessed: 02-Feb-2018].

[9] P. Gauché, J. Rudman, M. Mabaso, W. A. Landman, T. W. von Backström, and A. C. Brent, "System value and progress of CSP," Sol. Energy, vol. 152, no. 2017, pp. 106-139, 2017.

[10] REN21, "Renewables 2016 Global Status Report," 2016.

[11] S. Grobbelaar, P. Gauche, and A. Brent, "Developing a competitive concentrating solar power industry in South Africa : Current gaps and recommended next steps," Dev. South. Afr., vol. 31, no. 3, pp. 475493, 2014.

[12] Solargis, "Solargis World GHI Map," 2016. [Online]. Available: http://solargis.com/assets/graphic/free-map/GHI/Solargis-WorldGHI-solar-resource-map-en.png. [Accessed: 30-Jun-2016].

[13] B. Li, "The Effects of New Technology Flexibility on Innovation
Performance in the Post- Implementation Age Department of Management," Int. J. Bus. Soc. Sci., vol. 6, no. 5, pp. 22-27, 2015.

[14] J. Markard, R. Raven, and B. Truffer, "Sustainability transitions: An emerging field of research and its prospects," Res. Policy, vol. 41, no. 2012, pp. 955-967, 2012.

[15] T. A. Brzustowski, The Way Ahead: Meeting Canada's Productivity Challenge. Ottawa: University of Ottawa Press, 2008.

[16] E. Scott, Technology Commercialization. Krakow: ES Technology Limited, 2012.

[17] A. Aslani, "Strategic variables of commercialization of renewable energy technologies," J. Renew. Sustain. Energy, vol. 7, no. 2, p. 23105,2015

[18] P. D. Lund, "Effects of energy policies on industry expansion in renewable energy," Renew. Energy, vol. 34, no. 1, pp. 53-64, 2009.

[19] J. Krupa and S. Burch, "A new energy future for South Africa: The political ecology of South African renewable energy," Energy Policy, vol. 39, no. 10, pp. 6254-6261, 2011.

[20] IEA and OECD, "Lessons from liberalised electricity markets," 2005.

[21] A. C. Brent and M. Pretorius, "Industrial and commercial opportunities to utilise concentrating solar thermal systems in South Africa," J. Energy South. Africa, vol. 22, no. 4, pp. 15-30, 2011.

[22] P. Gauché, T. W. Von Backström, and A. C. Brent, "A concentrating solar power value proposition for South Africa," J. Energy South. Africa, vol. 24, no. 1, pp. 67-76, 2013.

[23] M. Sager, D. Ellen, E. Ritchken, and S. Osborne, "Concentrated solar power: A strategic industrial development opportunity for South Africa," 2015.

[24] J. Relancio, A. Cuellar, G. Walker, and C. Ettmayr, "South African CSP projects under the REIPPP programme - Requirements, Challenges and Opportunities," AIP Conf. Proc., vol. 1734, no. 1, p. $11002,2016$.

[25] CSIR Energy Centre, "Least Cost Electricity Mix for South Africa Optimisation of the South African power sector until 2050," CRSES, 2017. [Online]. Available: http://www.crses.sun.ac.za/files/news/CSIR_BischofNiemz_pp.pdf. [Accessed: 02-Feb-2018].

[26] G. Prentice, "A strategic management framework for the commercialisation of multi-technology renewable energy systems: The case of concentrating solar power in South Africa," Masters thesis, Stellenbosch University, 2018.

[27] Eskom, "New Build Programme," 2017. [Online]. Available: http://www.eskom.co.za/Whatweredoing/NewBuild/Pages/New_Bui ld_Programme.aspx. [Accessed: 20-Nov-2017].

\section{BIOGRAPHIES}

Greg Prentice holds a Bachelor degree in engineering (Mechatronics), and a Masters degree in Engineering Management, at Stellenbosch University. He has also passed Level 1 of the CFA Programme.

Imke de Kock holds a Bachelor degree in engineering (Industrial), a Masters degree in philosophy (Futures Research), and is currently a $\mathrm{PhD}$ candidate in Industrial Engineering. She is a professionally registered Industrial Engineer with international experience in the execution and management of industrial engineering and engineering management projects.

Alan Brent is a registered professional engineer (chemical), with Masters degrees in Technology Management, Environmental Engineering, and Sustainable Development, and a $\mathrm{PhD}$ in Engineering Management. He has over twenty years of experience in industry, and is a professor at Stellenbosch University, University of Pretoria, and Victoria University of Wellington. 